\title{
Microorganisms and clinical outcomes of early- and late-onset ventilator-associated pneumonia at Srinagarind Hospital, a tertiary center in Northeastern Thailand
}

\author{
Pavarit Arayasukawat ${ }^{1}$, Apichart So-ngern ${ }^{2^{*}} \mathbb{0}$, Wipa Reechaipichitkul ${ }^{3}$, Worawat Chumpangern ${ }^{3}$,
} Itthiphat Arunsurat ${ }^{3}$, Pailin Ratanawatkul ${ }^{3}$ and Wanna Chuennok ${ }^{4}$

\begin{abstract}
Background: Ventilator-associated pneumonia (VAP) is a common nocosomial infection in intensive care unit (ICU). Local microbiological surveillance of pathogens and resistance patterns for early-onset VAP (EOVAP) and late-onset VAP (LOVAP) will help to choose appropriate empiric antibiotics.

Objective: To compare the multi-drug resistant (MDR) pathogens, treatment outcomes, and factors associated with hospital mortality of VAP.

Method: A cross-sectional study between 1 January 2015 and 31 December 2017 at Srinagarind hospital, Khon Kaen University was conducted. The demographic data, causative pathogens, hospital length of stay (LOS), ICU LOS, mechanical ventilator (MV) days, and hospital mortality were retrospectively reviewed.

Results: One hundred and ninety patients were enrolled; 42 patients (22\%) were EOVAP and 148 patients (78\%) were LOVAP. Acinetobacter baumannii was the most common pathogen in both groups (50\% EOVAP vs 52.7\% LOVAP). MDR pathogens were significant greater in LOVAP (81.8\%) than EOVAP (61.9\%) $(p=0.007)$. The EOVAP had a significantly better ICU LOS [median (interquartile range, IQR) $20.0(11.0,30.0)$ vs. $26.5(17.0,43.0)$ days], hospital LOS [median (IQR) $26.5(15.0,44.0)$ vs. $35.5(24.0,56.0)$ days] shorter MV days [median (IQR) $14.0(10.0,29.0)$ vs. $23.0(14.0,35.5)$ days] and lower hospital mortality $(16.7 \%$ vs $35.1 \%)$ than LOVAP $(p<0.05)$. The factor associated with hospital mortality was having simplified acute physiology (SAP) II score $\geq 40$ with an adjusted odds ratio (aOR) of 2.22 [95\% confidence interval (CI), 1.08-4.54, $p=0.02]$.

Conclusion: LOVAP had significantly higher MDR pathogens, MV days, ICU LOS, hospital LOS and hospital mortality than EOVAP. A broad-spectrum antibiotic to cover MDR pathogens should be considered in LOVAP. The factor associated with hospital mortality of VAP was a SAPII score $\geq 40$.
\end{abstract}

Keywords: Early-onset VAP, Late-onset VAP, Microbiology, Outcome, Mortality

*Correspondence: apicso@kku.ac.th

${ }^{2}$ Division of Sleep Medicine, Srinagarind Hospital, Faculty of Medicine, Khon Kaen University, Khon Kaen, Thailand

Full list of author information is available at the end of the article

\section{Background}

Pneumonia is the most common hospital-acquired infection with a prevalence of approximately $22 \%$ [1, 2]. Ventilator-associated pneumonia (VAP) is pneumonia developing after $48-72 \mathrm{~h}$ of endotracheal intubation [3-5]. VAP is the most common nosocomial infection, 
developed in about 5-40\% of mechanically ventilated patients [5-7]. Data from the International Nosocomial Infection Control Consortium (INICC) collected summary data from 50 countries including Southeast Asia during 2010-2015 indicated the VAP rate was 13.1 per 1000 mechanical ventilator (MV) days in the medical and surgical intensive care unit (ICU) [8]. Similar results of Reechaipichitkul et al. who determined that VAP rates in Srinagarind Hospital, Khon Kaen University, a tertiarycare hospital in northeastern Thailand were 13.6 and 12.6 per 1000 MV days in 2008 and 2009. This study also demonstrated that more than half of the costs of nocosomial treatment in 2008 and 2009 were the costs for hospital acquired pneumonia (HAP) and VAP, 16.8 and 17.5 million Baht [9]. Melsen et al. performed a meta-analysis and suggested that overall attributable mortality in mechanical ventilator patients from VAP was 13\% [10].

VAP was categorized into early-onset VAP (EOVAP) and late-onset VAP (LOVAP) depending upon when it occurred on which days after hospitalization. The cutoff point of a range 4-7 days onset varied across the studies [11-16]. Recent guideline for HAP and VAP management from The Infectious Disease Society of America (IDSA)/American Thoracic Society (ATS) and the International ERS/ESICM/ESCMID/ALAT use the cutoff point of 5 days after hospitalization $[2,17,18]$. It is believed that in EOVAP, the causative pathogens are not drug-resistant bacteria such as Streptococcus pneumoniae, Haemophilus influenzae, antibiotic-sensitive enteric gram-negative bacilli or methicillin-sensitive Staphylococcus aureus (MSSA). There is a greater risk that the causative pathogens in LOVAP are multi-drug resistant (MDR) such as Acinetobacter baumannii, Pseudomonas aeruginosa, methicillin-resistant $S$. aureus (MRSA), extended-spectrum beta-lactamase (ESBL)-producing bacteria and other gram-negative bacilli $[5,17,19,20]$. The prevalence of MDR pathogens between EOVAP and LOVAP in several studies remained a controversy. Several studies demonstrated that EOVAP had a significantly lower prevalence of MDR pathogens [21-23]. Subsequent studies, however, did not show a significant difference in MDR pathogens between EOVAP and LOVAP groups [11, 12, 14, 24].

Therefore, this study was conducted and aimed to compare the pathogens, clinical characteristics, treatment outcomes between EOVAP and LOVAP groups, and factors associated with hospital mortality.

\section{Methods}

A cross-sectional study between 1 January 2015 and 31 December 2017 was conducted at Srinagarind Hospital, Faculty of Medicine, Khon Kaen University, a 1466bed tertiary care center in Northeast Thailand. In our hospital, patients who underwent mechanical ventilator received VAP bundle care as following: (1) endotracheal tube suctioning every $2 \mathrm{~h}$, (2) sedation keeping Richmond Agitation Sedation Scale (RASS) of 0 to -1 , (3) oral decontamination with $0.2 \%$ chlorhexidine, (4) aspiration precaution with head elevation of $30^{\circ}-45^{\circ}$ and (5) hand hygiene either with $4 \%$ chlorhexidine soap and water or with alcohol-based hand rub. In a case of VAP development; infection control ward nurses (ICWNs) reported all patients' data to infectious control (IC) unit system. We retrieved all VAP patient data from these recordings. The study was approved by the Human Research Ethics Committee, Khon Kaen University (approval number HE611281).

\section{Study subjects}

VAP was diagnosed by the following criteria: (1) a pulmonary infection occurring $48 \mathrm{~h}$ after mechanical ventilation (2) new pulmonary infiltration on chest radiograph (3) at least two of the three following characteristics: temperatures $>38.3{ }^{\circ} \mathrm{C}$ or $<36.5{ }^{\circ} \mathrm{C}$, purulent tracheal secretions, and leukocytosis (white blood cell $>12,000$ cells $/ \mathrm{mm}^{3}$ ) or leukopenia (white blood cell $<4000$ cells/ $\left.\mathrm{mm}^{3}\right)[4,25]$. The exclusion criteria were as following: (1) patients who had previous abnormal chest imaging including pulmonary edema, adult respiratory distress syndrome, pulmonary embolism, alveolar hemorrhage, pulmonary tuberculosis, and recent pneumonia. (2) Immunocompromised patients who received any immunosuppressive agents, chemotherapy, or prednisolone equivalence $\geq 15 \mathrm{mg} /$ day.

\section{Data collection}

The medical records of demographic data, hospital department, laboratory results, chest radiological findings, microbiological profiles, tracheostomy tube placement, hospital length of stay (LOS), intensive care unit (ICU) LOS, mechanical ventilator (MV) days and hospital mortality were reviewed.

\section{Definition and outcome}

EOVAP was VAP developed before 5 calendar days of hospitalization while LOVAP was VAP occurred at least 5 calendar days of hospitalization. MDR bacteria were defined as organisms that resisted at least 3 classes of antibiotics [26]. MDR pathogens included ESBL-producing bacteria, carbapenem-resistant Enterobacteriaceae (CRE), MRSA, and other MDR bacteria that were reported from the microbiological laboratory. The causative pathogens were defined as one or more of the following: (1) an isolated organism from hemoculture (2) an isolated organism from pleural effusion (3) an isolated numerous growth organism on a semiquantitative 
method or isolated organism on the quantitative method i.e. endotracheal aspirate $>10^{5}$ colony-forming unit $(\mathrm{CFU}) / \mathrm{ml}$, bronchoalveolar lavage $>10^{4} \mathrm{CFU} / \mathrm{ml}$ or protected specimen brush $\geq 10^{3} \mathrm{CFU} / \mathrm{ml}$. Hospital mortality was death occurring during the same admission of VAP diagnosis.

Empiric antibiotic therapy was prescribed according to local antibiogram and local data [9]. The commonly used empiric antibiotics for VAP were carbapenems, colistin and piperacillin/tazobactam. The causative pathogens and drug susceptibility tests were reported approximately $72 \mathrm{~h}$ after treatment. The proper antibiotic use was defined as the causative pathogens were susceptible to the initial empiric antibiotics.

The primary outcome was to compare the MDR pathogens between EOVAP and LOVAP. The secondary outcomes were to compare causative pathogens, hospital length of stay (LOS), ICU LOS, MV days, and hospital mortality between EOVAP and LOVAP. Factors associated with hospital mortality of VAP were identified.

\section{Statistical analysis}

The categorical data were shown as numbers and percentages. The normal distributed continuous data were presented as mean and standard deviation (SD) while the non-normal distributed data were presented as the median and interquartile range (IQR). A comparison of category data used the Chi-square test and Fisher's exact test depending on data. The nonparametric data used the Mann-Whitney $U$ test for comparison. The factors associated with hospital mortality in VAP subjects were evaluated by univariate logistic regression analysis. The stepwise backward multiple logistic regression analysis of factors with a $p$-value $<0.2$ on univariate analysis or factors with previous reports of clinical significance were performed. Crude odds ratio (COR) and adjusted odds ratio (aOR) with their $95 \%$ confidence intervals $(\mathrm{CI})$ were demonstrated. A $p$-value of less than 0.05 was considered statistically significant. The statistical analysis was performed by Stata version 10.1 (StataCorp, College Station Texas, USA).

\section{Results}

Patients

During the study period, 190 patients were diagnosed with VAP. Forty-two patients were EOVAP and 148 patients were LOVAP. The mean (SD) age of these was 64.3 (16.2) years. Males were 127 patients $(66.8 \%)$ and females were 63 patients (33.2\%). One hundred and seven patients $(56.3 \%)$ were admitted to the Medicine Department (96 patients (50.5\%) in medical ICU ward and 11 patients (5.8\%) in general medicine ward). Eightythree patients $(43.7 \%)$ were admitted to the Surgical
Department (73 patients (38.4\%) in surgical ICU ward and 10 patients (5.3\%) in general surgery ward). One hundred and forty-eight patients (77.9\%) had an underlying disease. The common underlying diseases were hypertension (41.6\%), diabetes mellitus (27.4\%), cardiovascular disease (26.8\%). The mean (SD) of the simplified acute physiology (SAP) II score was 43.7 (13.3). Lobar pneumonia was the most common finding on chest radiography which was found in 145 patients (76.3\%). Pleural effusion developed in 54 patients (28.4\%). The demographic data of EOVAP and LOVAP patients were shown in Table 1. LOVAP patients had a higher mean age and more comorbidities than EOVAP patients while the chest radiographic findings were similar between groups.

\section{Primary outcome}

The causative pathogens were mostly gram-negative bacteria (97.4\%) while gram-positive bacteria were isolated $2.6 \%$. The most common pathogens were $A$. baumannii (52.1\%), Klebsiella pneumoniae (15.3\%),

\section{Table 1 Demographic data of early-onset VAP $(n=42)$} and late-onset VAP $(n=148)$

\begin{tabular}{lcc}
\hline Characteristics & $\begin{array}{l}\text { Early-onset VAP } \\
\mathbf{n}(\%)\end{array}$ & $\begin{array}{l}\text { Late-onset VAP } \\
\mathbf{n}(\%)\end{array}$ \\
\hline Mean age in years (SD) & $58.5(16.9)$ & $65.9(15.7)$ \\
Male & $34(81)$ & $93(62.8)$ \\
Ward & & \\
Medical ICU & $14(33.3)$ & $82(55.4)$ \\
Surgical ICU & $21(50.0)$ & $52(35.1)$ \\
General medicine ward & $3(7.1)$ & $8(5.4)$ \\
General surgery ward & $4(9.5)$ & $6(4.1)$ \\
Underlying diseases & $28(66.7)$ & $120(81.1)$ \\
Hypertension & $17(40.5)$ & $62(41.9)$ \\
Diabetes mellitus & $10(23.8)$ & $42(28.4)$ \\
Cardiovascular disease & $11(26.2)$ & $40(27.0)$ \\
Renal failure & $4(9.5)$ & $37(25.0)$ \\
Neurological disease & $6(14.3)$ & $22(14.9)$ \\
Dyslipidemia & $4(9.5)$ & $17(11.5)$ \\
Lung disease & $6(14.3)$ & $13(8.8)$ \\
Gastrointestinal disease & $2(4.8)$ & $11(7.4)$ \\
Other & $1(2.4)$ & $17(11.5)$ \\
Hospitalized within 90 days & $4(9.5)$ & $10(6.8)$ \\
Antibiotic therapy in the prior & $22(52.4)$ & $101(68.2)$ \\
month & & $42.4(12.9)$ \\
Mean SAP II score (SD) & $40.9(14.1)$ & $111(75.0)$ \\
Chest radiographic finding & & $37(25.0)$ \\
Lobar pneumonia & $34(80.9)$ & $42(28.4)$ \\
Multilobar pneumonia & $8(19.0)$ & \\
Pleural effusion & $12(28.6)$ & \\
\hline
\end{tabular}

VAP ventilator-associated pneumonia, $S D$ standard deviation, ICU intensive care unit, IQR interquartile range, SAP II score simplified acute physiology II score 
Stenotrophomonas maltophilia (13.2\%), P. aeruginosa (8.9\%). The MDR pathogens were identified $77.4 \%$; $3.7 \%$ of ESBL-producing bacteria, $5.3 \%$ of CRE, $1.6 \%$ of MRSA and $66.8 \%$ of other MDR gram-negative bacteria. The MDR bacteria were found $61.9 \%$ in the EOVAP and $81.8 \%$ in LOVAP. The LOVAP had significantly more MDR pathogens than EOVAP $(p=0.007)$. The data were shown in Table 2. The proper antibiotics were used to treat 130 patients $(68.4 \%) ; 26$ patients $(61.9 \%)$ of EOVAP and 104 patients $(70.3 \%)$ of LOVAP. The proportion of proper antibiotics was similar between groups $(p=0.30)$.

\section{Secondary outcomes}

The median (IQR) duration of MV day was 22.0 (12.0, 34.0) days. The median (IQR) duration of MV day was significantly longer in LOVAP $[23.0(14.0,35.5)$ vs 14.0 $(10.0,29.0)$ days); $p=0.03)$. The median (IQR) ICU LOS was $25.0(15.0,42.0)$ days. The median (IQR) ICU LOS was significantly longer in LOVAP [26.5 (17.0, 43.0) vs $20.0(11.0,30.0)$ days; $p=0.02$ ]. The median (IQR) hospital LOS was $34.0(23.0,53.0)$ days. The median (IQR) hospital LOS was significantly longer in LOVAP [35.5 $(24.0,56.0)$ vs $26.5(15.0,44.0)$ days; $p=0.01]$.
Tracheostomy was performed in $30.5 \%$ (38.1\% of EOVAP and $28.4 \%$ of LOVAP). The overall hospital mortality during the study period was $31.1 \%$. The hospital mortality was significantly greater in LOVAP $(35.1 \%$ vs $16.7 \% ; p=0.02)$. The data were shown in Table 3.

\section{Factor associated hospital mortality}

Univariate and multivariate analysis were performed to assess factors associated with hospital mortality. On univariate analysis, the patients who were of an age $\geq 60$ years $(\mathrm{cOR}=2.19 ; 95 \% \mathrm{CI} 1.11-4.33 ; p=0.02)$, were admitted in the medical ICU $(\mathrm{cOR}=2.28 ; 95 \%$ CI $1.20-4.29 ; p=0.01)$, having a SAPII score $\geq 40$ ICU $(\mathrm{cOR}=2.49 ; 95 \%$ CI $1.28-4.86 ; p=0.007)$, receiving improper antibiotics $(\mathrm{cOR}=2.27 ; 95 \% \mathrm{CI} 1.10-4.68$; $p=0.02)$, or were late-onset VAP $(\mathrm{cOR}=2.71 ; 95 \% \mathrm{CI}$ $1.12-6.52 ; p=0.02)$ were statistically associated with hospital mortality of VAP patients. On stepwise backward multivariate analysis, having a SAPII score $\geq 40$ was the statistically significant factor associated with hospital mortality $(\mathrm{aOR}=2.22 ; 95 \%$ CI $1.08-4.54$; $p=0.02)$. The data were shown in Table 4.

Table 2 Microorganisms identified in early-onset VAP $(n=42)$ and late-onset VAP $(n=148)$

\begin{tabular}{|c|c|c|c|}
\hline Microorganism & $\begin{array}{l}\text { Early-onset VAP } \\
n(\%)\end{array}$ & $\begin{array}{l}\text { Late-onset VAP } \\
\mathrm{n}(\%)\end{array}$ & p-value \\
\hline Gram-negative organism & $40(95.2)$ & $145(97.9)$ & 0.31 \\
\hline Acinetobacter baumannii & $21(50.0)$ & $78(52.7)$ & 0.76 \\
\hline MDR Acinetobacter baumannii & $20(47.6 \%)$ & $73(49.3)$ & 0.84 \\
\hline Klebsiella pneumoniae & $8(19.0)$ & $21(14.2)$ & 0.44 \\
\hline MDR Klebsiella pneumoniae & $1(2.4)$ & $18(12.2)$ & \\
\hline ESBL-Klebsiella pneumoniae & $0(0.0)$ & $5(3.4)$ & \\
\hline CRE Klebsiella pneumoniae & $1(2.4)$ & $9(6.1)$ & \\
\hline Pseudomonas aeruginosa & $3(7.1)$ & $14(9.5)$ & 0.64 \\
\hline MDR Pseudomonas aeruginosa & $1(2.4)$ & $2(1.4)$ & \\
\hline Stenotrophomonas maltophilia & $2(4.8)$ & $23(15.5)$ & 0.07 \\
\hline MDR Stenotrophomonas maltophilia & $2(4.8)$ & $22(14.9)$ & \\
\hline Enterobacterspp. & $2(4.8)$ & $2(1.4)$ & 0.17 \\
\hline MDR Enterobacter spp. & $1(2.4)$ & $2(1.4)$ & \\
\hline ESBL-Enterobacter spp. & $1(2.4)$ & $1(2.4)$ & \\
\hline Other gram-negative organisms & $4(1.7)$ & $7(4.73)$ & \\
\hline Gram-positive organism & $2(4.8)$ & $3(2.0)$ & 0.24 \\
\hline Staphylococcus aureus & $1(2.4)$ & $2(1.4)$ & 0.31 \\
\hline MRSA & $1(2.4)$ & $2(1.4)$ & 0.64 \\
\hline Other gram-positive organisms & $1(2.4)$ & $1(0.7)$ & 0.33 \\
\hline Multidrug-resistant pathogens ${ }^{* *}$ & $26(61.9)$ & $121(81.8)$ & $0.007^{*}$ \\
\hline
\end{tabular}

VAP ventilator-associated pneumonia, ESBL extended-spectrum beta-lactamase, CRE carbapenem-resistant Enterobacteriaceae, MRSA methicillin-resistant Staphylococcus aureus

${ }^{*} \mathrm{p}$-value $<0.05$

**Multidrug-resistant pathogens included ESBLs, CRE, MRSA, and other MDR organisms 
Table 3 Outcomes of treatment in early-onset VAP $(n=42)$ and late-onset VAP $(n=148)$

\begin{tabular}{llll}
\hline Outcomes & Early-onset VAP & Late-onset VAP & p-value \\
\hline Median duration MV day (day, IQR) & $14.0(10.0,29.0)$ & $23.0(14.0,35.5)$ & $0.03^{*}$ \\
Median ICU LOS (day, IQR) & $20.0(11.0,30.0)$ & $26.5(17.0,43.0)$ & $0.02^{*}$ \\
Median hospital LOS (day, IQR) & $26.5(15.0,44.0)$ & $35.5(24.0,56.0)$ & $0.01^{*}$ \\
Performed tracheostomy (n. \%) & $16.0(38.1)$ & $42.0(28.4)$ & 0.22 \\
Hospital mortality (n, \%) & $7.0(16.7)$ & $52.0(35.1)$ & $0.02^{*}$ \\
\hline
\end{tabular}

VAP ventilator-associated pneumonia, $M V$ mechanical ventilator, ICU intensive care unit, IQR interquartile range, $L O S$ length of stay

${ }^{*}$ p-value $<0.05$

Table 4 Factors associated with hospital mortality in VAP patients

\begin{tabular}{llc}
\hline Factors & Crude OR (95\% Cl) & Adjusted OR (95\% Cl) \\
\hline Age $\geq 60$ years & $2.19(1.11-4.33)$ & - \\
Having underlying diseases & $0.99(0.47-2.08)$ & - \\
Patient at medical ICU & $2.28(1.20-4.29)$ & - \\
Having SAP II score $\geq 40$ & $2.49(1.28-4.86)$ & $2.22(1.08-4.54)$ \\
Resistant gram-negative organisms & $1.04(0.51-2.13)$ & - \\
Receiving improper antibiotics & $2.27(1.10-4.68)$ & - \\
Late-onset VAP & $2.71(1.12-6.52)$ & -
\end{tabular}

VAP ventilator-associated pneumonia, OR odds ratio, Cl confidence interval, ICU intensive care unit, SAP II score simplified acute physiology II score

*p-value for $95 \% \mathrm{Cl}$ of adjusted OR

\section{Discussion}

The study revealed that the most common pathogens were gram-negative bacteria. A. baumannii, K. pneumoniae, $P$. aeruginosa were common pathogens in both groups while $S$. maltophilia was increased in LOVAP. The pathogens from this study did not differ between EOVAP and LOVAP. The results of this study were similar to other tertiary centers in Thailand $[27,28]$. Of these, A. baumannii, $K$. pneumoniae, $P$. aeruginosa were the common pathogens of VAP. These studies, however, did not address the causative pathogens into EOVAP and LOVAP. Three studies from different tertiary-care centers of India had results similar to our study [14, 15, 29]. $A$. baumannii, K. pneumonia and $P$. aeruginosa were common pathogens in both EOVAP and LOVAP. The pathogens of EOVAP from this study differed from pathogens mentioned in the recent guideline [17]. The results supported that empiric antibiotics should be guided by a local distribution of pathogens that are recommended by the Management of Adults with Hospital-acquired and Ventilator-associated Pneumonia in 2016 by IDSA/ ATS guideline [2]. Papazian et al. suggested that microbiological confirmation is strongly recommended when considering a diagnosis of VAP and pathogens may vary depending on many factors including the duration of $\mathrm{MV}$, hospital LOS, ICU LOS, previous antibiotics exposure, the occurrence of epidemic phenomena in a given ICU and local distribution of organisms [5].
Gram-positive bacteria were identified in only $2.6 \%$ and most of them were MRSA. The prevalence of drugresistance gram-positive bacteria in this study was markedly lower as compared to the study of the pathogens of VAP in Thailand by Chittawatanarat et al., Inchai et al. and Werarak et al. [27, 28, 30]. Reechaipichitkul et al. conducted a study of the causative organisms of VAP in the same center during 2008-2009. The study indicated MRSA was responsible for $6-7 \%$ of the total causative pathogens [9]. The majority of $S$. aureus colonization in the respiratory tract is in the nares and throat. Chlorhexidine is a topical antiseptic, which is most active against gram-positive bacteria [31]. Our center has applied selective oral decontamination (SOD) with chlorhexidine since 2011. This might have reduced the incidence of VAP due to MRSA.

Inappropriate and delayed empiric antibiotics are associated with higher mortality in VAP patients [32$34]$. In our center, the empiric antibiotic was based on the previous local study in 2008 [9]. The study demonstrated that gram-negative bacteria were the majority of VAP causative pathogen. The three most common pathogens were A. baumannii, P. aeruginosa and K. pneumoniae. A. Baumannii mostly resisted carbapenems, cefoperazone/sulbactam, piperacillin/tazobactam but were still susceptible to colistin. $P$. aeruginosa resisted mostly to carbapenems but were still susceptible to ceftazidime, piperacillin/tazobactam and levofloxacin. 
Forty-seven percent of $K$. pneumoniae was ESBL producer. The carbapenems had activity against ESBL producing $K$. pneumoniae [9]. The purpose of differentiation of VAP into EOVAP and LOVAP was to guide empiric antibiotic treatment to cover MDR bacteria. The study found that LOVAP had a significantly higher proportion of MDR pathogens than EOVAP $(p=0.007)$. The results endorsed the Management of Adults with Hospital-acquired and Ventilator-associated Pneumonia in 2016 by IDSA/ATS suggested that VAP developed after 5 days of hospitalization had a greater risk of MDR pathogen presence than VAP developed earlier [2]. Therefore empiric broad-spectrum antibiotics against MDR pathogens were recommended for LOVAP.

Furthermore, this current study demonstrated that LOVAP had significantly longer MV days, ICU LOS, and hospital LOS than EOVAP. The hospital mortality was significantly greater in LOVAP ( $35.1 \%$ vs $16.7 \%, p=0.02)$. These worse outcomes of LOVAP were also observed by Khan et al. [24]. The implementation of VAP prevention might reduce the cost of hospitalization and unnecessary mortality, especially in LOVAP [35].

A meta-analysis from Melsen et al. suggested that overall attributable mortality from VAP was $13 \%$ and the higher mortality were found in surgical patients, acute physiology and chronic health evaluation (APACHE) score of 20-29 and SAPS II score of 35-58 [10]. Bekaert et al.revealed the SAPS II score of 28-40 was significantly greatest associated with ICU death per additional day since the onset VAP [36]. Similar to our study, on stepwise backward multivariate analysis, a SAPII score $\geq 40$ was significantly associated with hospital mortality of VAP patients.

The strengths of this study were that the recorded data were complete because VAP was under regular surveillance of our institute by ICWNs and confirmed by the IC unit.

This study had some limitations. First, the sample size is small, especially in EOVAP. This affected the statistical power. Second, this was a retrospective study, some data might be difficult to determine such as previous antibiotic exposure within 90 days, prior hospitalization preceding 90 days. These factors are associated with MDR pathogen infections $[2,37]$. Third, the results of this study were unable to be applied to VAP in immunocompromised patients. Fourth, this study was from a single tertiary center, which had some limitations for the application in general hospitals. Pathogens and resistance patterns could vary between hospitals, regions and countries [2]. The local pathogens and pattern resistance of each hospital were the crucial factors for the selection of initial empiric antibiotics.

\section{Conclusion}

In conclusion, LOVAP was significantly higher MDR pathogens, MV days, ICU LOS, hospital LOS and hospital mortality than EOVAP. A broad-spectrum antibiotic to cover MDR pathogens should be considered in LOVAP. The factor associated with hospital mortality of VAP was a SAPII score $\geq 40$.

\begin{abstract}
Abbreviations
VAP: Ventilator-associated pneumonia; ICU: Intensive care unit; EOVAP: Early-onset ventilator-associated pneumonia; LOVAP: Late-onset ventilatorassociated pneumonia; LOS: Length of stay; MV: Mechanical ventilator; MDR: Multi-drug resistant; SAP II score: Simplified acute physiology II score; INICC: International Nocosomial Infection Control Consortium; IDSA: Infectious Disease Society of America; ATS: American Thoracic Society; ERS: European Respiratory Society; ESICM: European Society of Intensive Care Medicine; ESCMID: European Society of Clinical Microbiology and Infectious Diseases; ALAT: Latin American Thoracic Association; IC: Infectious control; ICWNs: Infection control ward nurses; SOD: Selective oral decontamination; MSSA: Methicillin-sensitive Staphylococcus aureus; MRSA: Methicillin-resistant Staphylococcus aureus; ESBL: Extended-spectrum beta-lactamase; CRE: Carbapenem-resistant Enterobacteriaceae; CFU: Colony-forming unit; ml: Millilitre; mg: Milligram; SD: Standard deviation; IQR: Interquartile range; aOR: Crude odds ratio; COR: Adjusted odds ratio; Cl: Confidence interval.
\end{abstract}

\section{Acknowledgements}

The authors gratefully thank Professor James Arthur Will for editing the manuscript via the Faculty of Medicine Publication Clinic, Khon Kaen University, Thailand.

\section{Authors' contributions}

PA, AS, WR contributed to the study design, statistical analysis, data interpretation, manuscript preparation and critical revision of intellectual content. WC1, IA contributed to data interpretation and manuscript preparation. PR contributed to statistical analysis and data interpretation. WC2 contributed to data acquisition and interpretation. All authors read and approved the final manuscript.

\section{Funding}

This research did not receive any funding sources.

\section{Availability of data and materials}

The datasets used and/or analyzed in this study are available from the corresponding author on reasonable request.

\section{Ethics approval and consent to participate}

This study was approved by the Human Research Ethics Committee, Khon Kaen University (Approval Number HE611281). The informed consent was waived by ethics committee due to the anonymized routine surveillance data derived from our hospital infection control registry were retrospectively reviewed. The patient's data access was permitted by the infection control committee.

\section{Consent for publication}

According to no individual patient data is presented in our study, consent for publication is not applicable.

\section{Competing interests}

All authors have no competing interests.

\section{Author details}

${ }^{1}$ Department of Medicine, Srinagarind Hospital, Faculty of Medicine, Khon Kaen University, Khon Kaen, Thailand. ${ }^{2}$ Division of Sleep Medicine, Srinagarind Hospital, Faculty of Medicine, Khon Kaen University, Khon Kaen, Thailand.

${ }^{3}$ Division of Pulmonary and Critical Care Medicine, Srinagarind Hospital,

Faculty of Medicine, Khon Kaen University, Khon Kaen, Thailand. ${ }^{4}$ Infectious 
Control Unit, Srinagarind Hospital, Faculty of Medicine, Khon Kaen University, Khon Kaen, Thailand.

Received: 17 June 2020 Accepted: 21 January 2021

Published online: 30 January 2021

\section{References}

1. Magill SS, Edwards JR, Bamberg W, Beldavs ZG, Dumyati G, Kainer MA et al. Multistate point-prevalence survey of health care-associated infections. N Engl J Med. 2014;370(13):1198-208.

2. Kalil AC, Metersky ML, Klompas M, Muscedere J, Sweeney DA, Palmer $L B$, et al. Management of adults with hospital-acquired and ventilatorassociated pneumonia: 2016 Clinical Practice Guidelines by the Infectious Diseases Society of America and the American Thoracic Society. Clin Infect Dis. 2016;63(5):e61-111.

3. Tablan OC, Anderson LJ, Besser R, Bridges C, Hajjeh R. Guidelines for preventing health-care-associated pneumonia, 2003: recommendations of CDC and the Healthcare Infection Control Practices Advisory Committee. MMWR Recomm Rep. 2004;53(Rr-3):1-36.

4. American Thoracic Society (ATS) and the Infectious Disease Society of American (IDSA). Guidelines for the management of adults with hospital-acquired, ventilator-associated, and healthcare-associated pneumonia. Am J Respir Crit Care Med. 2005;171(4):388-416.

5. Papazian L, Klompas M, Luyt CE. Ventilator-associated pneumonia in adults: a narrative review. Intensive Care Med. 2020;46(5):888-906.

6. Rello J, Ollendorf DA, Oster G, Vera-Llonch M, Bellm L, Redman R, et al. Epidemiology and outcomes of ventilator-associated pneumonia in a large US database. Chest. 2002;122(6):2115-21.

7. Hunter JD. Ventilator associated pneumonia. BMJ (Clin Res Ed). 2012;344:e3325.

8. Rosenthal VD, Al-Abdely HM, El-Kholy AA, AIKhawaja SAA, Leblebicioglu $\mathrm{H}$, Mehta Y, et al. International Nosocomial Infection Control Consortium report, data summary of 50 countries for 2010-2015: device-associated module. Am J Infect Control. 2016;44(12):1495-504.

9. Reechaipichitkul W, Phondongnok S, Bourpoern J, Chaimanee P. Causative agents and resistance among hospital-acquired and ventilator-associated pneumonia patients at Srinagarind Hospital, northeastern Thailand. Southeast Asian J Trop Med Public Health. 2013;44(3):490-502.

10. Melsen WG, Rovers MM, Groenwold RH, Bergmans DC, Camus C, Bauer $\mathrm{TT}$, et al. Attributable mortality of ventilator-associated pneumonia: a meta-analysis of individual patient data from randomised prevention studies. Lancet Infect Dis. 2013;13(8):665-71.

11. Restrepo MI, Peterson J, Fernandez JF, Qin Z, Fisher AC, Nicholson SC. Comparison of the bacterial etiology of early-onset and late-onset ventilator-associated pneumonia in subjects enrolled in 2 large clinical studies. Respir Care. 2013;58(7):1220-5.

12. Giantsou E, Liratzopoulos N, Efraimidou E, Panopoulou M, Alepopoulou E, Kartali-Ktenidou S, et al. Both early-onset and late-onset ventilatorassociated pneumonia are caused mainly by potentially multiresistant bacteria. Intensive Care Med. 2005;31(11):1488-94.

13. Hedrick TL, Smith RL, McElearney ST, Evans HL, Smith PW, Pruett TL, et al. Differences in early- and late-onset ventilator-associated pneumonia between surgical and trauma patients in a combined surgical or trauma intensive care unit. J Trauma. 2008;64(3):714-20.

14. Jakribettu R, Boloor R, Suresh S. Comparison of microbiological profile of pathogens isolated from early-onset and late-onset ventilatorassociated pneumonia in a tertiary care center. Trop J Med Res. 2016;19(1):14-9.

15. Saroj G, Sangeetha KT, Vasudha CL. Microbial profile of early and late onset ventilator associated pneumonia in the intensive care unit of a tertiary care hospital in Bangalore, India. J Clin Diagnost Res. 2013;7(11):2462-6.

16. Gastmeier P, Sohr D, Geffers C, Rüden H, Vonberg RP, Welte T. Early- and late-onset pneumonia: is this still a useful classification? Antimicrob Agents Chemother. 2009;53(7):2714-8.

17. Torres A, Niederman MS, Chastre J, Ewig S, Fernandez-Vandellos P, Hanberger $\mathrm{H}$, et al. Summary of the international clinical guidelines for the management of hospital-acquired and ventilator-acquired pneumonia. ERJ Open Res. 2018. https://doi.org/10.1183/23120541.00028-2018.

18. Torres A, Niederman MS, Chastre J, Ewig S, Fernandez-Vandellos P, Hanberger $\mathrm{H}$, et al. International ERS/ESICM/ESCMID/ALAT guidelines for the management of hospital-acquired pneumonia and ventilatorassociated pneumonia: guidelines for the management of hospitalacquired pneumonia (HAP)/ventilator-associated pneumonia (VAP) of the European Respiratory Society (ERS), European Society of Intensive Care Medicine (ESICM), European Society of Clinical Microbiology and Infectious Diseases (ESCMID) and Asociacion Latinoamericana del Torax (ALAT). Eur Respir J. 2017;50(3):1700582.

19. Kalanuria AA, Ziai W, Mirski M. Ventilator-associated pneumonia in the ICU. Crit Care (Lond, Engl). 2014;18(2):208.

20. Park DR. The microbiology of ventilator-associated pneumonia. Respir Care. 2005;50(6):742-63.

21. Kollef MH, Silver P, Murphy DM, Trovillion E. The effect of late-onset ventilator-associated pneumonia in determining patient mortality. Chest. 1995;108(6):1655-62.

22. Trouillet JL, Chastre J, Vuagnat A, Joly-Guillou ML, Combaux D, Dombret MC, et al. Ventilator-associated pneumonia caused by potentially drug-resistant bacteria. Am J Respir Crit Care Med. 1998;157(2):531-9.

23. Hosamirudsari H, Forghani S, Samaneh A. Multi-drug resistant ventilator associated pneumonia: risk factors and outcomes. Can J Infect Control. 2018;33(1):20-4.

24. Khan R, Al-Dorzi HM, Tamim HM, Rishu AH, Balkhy H, El-Saed A, et al. The impact of onset time on the isolated pathogens and outcomes in ventilator associated pneumonia. J Infect Public Health. 2016;9(2):161-71.

25. Torres A, El-Ebiary M, Padró L, Gonzalez J, de la Bellacasa JP, Ramirez J, et al. Validation of different techniques for the diagnosis of ventilatorassociated pneumonia. Comparison with immediate postmortem pulmonary biopsy. Am J Respir Crit Care Med. 1994;149(2 Pt 1):324-31.

26. Magiorakos AP, Srinivasan A, Carey RB, Carmeli Y, Falagas ME, Giske CG, et al. Multidrug-resistant, extensively drug-resistant and pandrugresistant bacteria: an international expert proposal for interim standard definitions for acquired resistance. Clin Microbiol Infect. 2012;18(3):268-81.

27. Werarak P, Kiratisin P, Thamlikitkul V. Hospital-acquired pneumonia and ventilator-associated pneumonia in adults at Siriraj Hospital: etiology, clinical outcomes, and impact of antimicrobial resistance. J Med Assoc Thailand. 2010;93(Suppl 1):S126-38.

28. Chittawatanarat K, Jaipakdee W, Chotirosniramit N, Chandacham K, Jirapongcharoenlap T. Microbiology, resistance patterns, and risk factors of mortality in ventilator-associated bacterial pneumonia in a Northern Thai tertiary-care university based general surgical intensive care unit. Infect Drug Resist. 2014;7:203-10.

29. Dey A, Bairy I. Incidence of multidrug-resistant organisms causing ventilator-associated pneumonia in a tertiary care hospital: a nine months' prospective study. Ann Thor Med. 2007;2(2):52-7.

30. Inchai J, Pothirat C, Liwsrisakun C, Deesomchok A, Kositsakulchai W, Chalermpanchai N. Ventilator-associated pneumonia: epidemiology and prognostic indicators of 30-day mortality. Jpn J Infect Dis. 2015;68(3):181-6.

31. Koeman M, van der Ven AJ, Hak E, Joore HC, Kaasjager K, de Smet AG, et al. Oral decontamination with chlorhexidine reduces the incidence of ventilator-associated pneumonia. Am J Respir Crit Care Med. 2006;173(12):1348-55.

32. Luna CM, Vujacich P, Niederman MS, Vay C, Gherardi C, Matera J, et al. Impact of BAL data on the therapy and outcome of ventilator-associated pneumonia. Chest. 1997;111(3):676-85.

33. Kollef MH, Sherman G, Ward S, Fraser VJ. Inadequate antimicrobial treatment of infections: a risk factor for hospital mortality among critically ill patients. Chest. 1999;115(2):462-74.

34. Iregui M, Ward S, Sherman G, Fraser VJ, Kollef MH. Clinical importance of delays in the initiation of appropriate antibiotic treatment for ventilator-associated pneumonia. Chest. 2002;122(1):262-8.

35. Hellyer TP, Ewan V, Wilson P, Simpson AJ. The Intensive Care Society recommended bundle of interventions for the prevention of ventilatorassociated pneumonia. J Intensive Care Soc. 2016;17(3):238-43.

36. Bekaert M, Timsit JF, Vansteelandt S, Depuydt P, Vésin A, GarrousteOrgeas M, et al. Attributable mortality of ventilator-associated 
pneumonia: a reappraisal using causal analysis. Am J Respir Crit Care Med. 2011;184(10):1133-9.

37. Aliberti S, Di Pasquale M, Zanaboni AM, Cosentini R, Brambilla AM, Seghezzi S, et al. Stratifying risk factors for multidrug-resistant pathogens in hospitalized patients coming from the community with pneumonia. Clin Infect Dis. 2012;54(4):470-8.

\section{Publisher's Note}

Springer Nature remains neutral with regard to jurisdictional claims in published maps and institutional affiliations.
Ready to submit your research? Choose BMC and benefit from:

- fast, convenient online submission

- thorough peer review by experienced researchers in your field

- rapid publication on acceptance

- support for research data, including large and complex data types

- gold Open Access which fosters wider collaboration and increased citations

- maximum visibility for your research: over 100M website views per year

At BMC, research is always in progress.

Learn more biomedcentral.com/submissions 